\section{JURNAL ABDIMAS

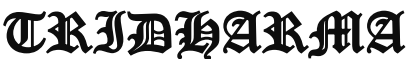

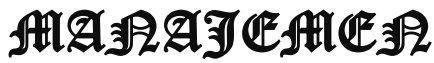

P-ISSN 0000-0000, E-ISSN 0000-0000

Jurnal ABDIMAS Vol. 1, No. 1,Agustus 2019, Hal (60-65)

@Prodi Manajemen Fakultas Ekonomi Universitas Pamulang

Email: abdimasjurnal.unpam@gmail.com Telp: (021) 741-2566

\title{
PROGRAM MENTORING DAN MOTIVATING DALAM MELATIH KEMANDIRIAN SISWA/I SEKOLAH MENENGAH KEJURUAN DARUSSALAM, CIPUTAT, TANGERANG SELATAN
}

\author{
Lismiatun, Fadillah, Novia Susanti, Putri Nilam Kencana \\ Dosen Ekonomi Fakultas Ekonomi Universitas Pamulang \\ Email : dosen01460@unpam.ac.id, dosen02197@unpam.ac.id \\ dosen00768@unpam.ac.id, dosen01877@unpam.ac.id
}

\begin{abstract}
ABSTRAK
Era globalisasi dan pesatnya perkembangan Teknologi Informasi (TI) saat ini menuntut generasi muda yang inovatif serta mampu menghadapi berbagai tantangan dan problematika sosial di usianya. Oleh karena itu perlu dilakukan pembekalan dengan berbagai cara menghadapi tantangan serta teknik menerapkan problem solving. Salah satu caranya yaitu melakukan kegiatan pengabdian kepada masyarakat, kali ini adalah tentang Mentoring dan Motivating Dalam Melatih Kemandirian Siswa/i Sekolah Menengah Kejuruan Darussalam, Ciputat, Tangerang Selatan.

Tujuan pengabdian ini adalah untuk membantu memberikan arahan, membuka paradigma pola pikir siswa/i, memberikan semangat dan motivasi kepada seluruh siswa/i dalam menentukan langkah yang akan ditentukan. Sehingga pemikiran siswa menjadi terbuka dan mampu mengatur arah hidup mereka secara mandiri dan bermanfaat untuk orang lain dimasa mendatang.

Kegiatan yang dilakukan lebih kepada interaktif kepada pada siswa/i dengan memberikan arahan, bimbingan, tanya jawab bagaimana cara-cara yang paling mudah untuk dilakukan para siswa/i dalam pengambilan keputusan. Sebelum kegiatan berlangsung tim pengabdian melakukan tahap sosialisasi terlebih dahulu yaitu melakukan silaturahmi dengan Ketua Yayasan, menyampaikan maksud dan tujuan pengabdian ini, sekaligus untuk menjalin kerjasama serta menentukan jadwal kegiatan pengabdian. Pelaksana kegiatan pengabdian pada masyarakat adalah Dosen Universitas Pamulang, Fakultas Ekonomi, Program Studi Manajemen sebanyak 10 orang.

Kesimpulan dari kegiatan pengabdian ini adalah sebagian besar para siswa/i belum berani tampil di depan umum, mereka juga sungkan, malu untuk menyampaikan pendapat, serta beberapa siswa/i mengalami kebingunggan dalam menentukan langkah berikutnya setelah lulus dari sekolah. Dengan kegiatan ini diharapkan dapat membantu melatih para siswa/i menyampaikan pendapat, harapan, keinginan, berani mengambil sikap dan keputusan, memiliki rasa percaya diri serta memotivasi mereka agar menjadi generasi muda yang inovatif, kreatif, sprortif, yang menjadi kebanggaan orang tua, sekolah dan masyarakat sekitarnya.
\end{abstract}




\section{JURNAL ABDIMAS

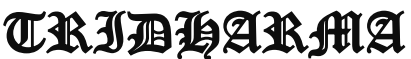

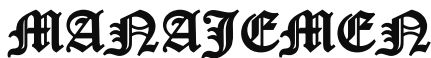

P-ISSN 0000-0000, E-ISSN 0000-0000

Jurnal ABDIMAS Vol. 1, No. 1,Agustus 2019, Hal (60-65)

@Prodi Manajemen Fakultas Ekonomi Universitas Pamulang

Email: abdimasjurnal.unpam@ gmail.com Telp: (021) 741-2566

\title{
Kata Kunci: Mentoring, Motivasi, Inovatif
}

\begin{abstract}
ABSTRAC
Globalizations and the rapid development of the Information and Technology (IT) at this time requires innovative young people who are able to overcome various challenges and social problems in their age. Therefore it is necessary to do debriefing in various challenging ways and problem solving techniques. One of the activities of community service is about Mentoring and Motivating in Training at Sekolah Menegah Kejuruan Darussalam, Ciputat, South Tangerang.
\end{abstract}

The purpose of this service is to help provide direction, open the paradigm of the mindset of students, provide enthusiasm and motivation for all students in determining the steps to be determined. It is expected to be able to help others in the future.

The activities carried out were more than for students by giving direction, guidance, question and answer the easiest ways to do for students in making decisions. Before the activity took place, the service team conducted a socialization to first conduct a gathering with the Chair of the Foundation, to convey the purpose and purpose of this service, as well as to establish cooperation and determine the schedule of service activities. The total number of participant is 10 Lecturer from Pamulang University, Faculty of Economics, Department of Management.

The conclusion of this service activity is that most of the students have not dared to appear before age, they are also reluctant, embarrassed to discuss, and some students solve confusion in determining the next step after graduating from school. This activity is expected to help students express their opinions, hopes, desires, strive to make decisions and decisions, have self-confidence and motivate them to become a young generation that is innovative, creative, supportive, which is the pride of parents, schools and society surrounding area.

\section{Keywords: Mentoring, Motivation, Innovative}




\section{JURNAL ABDIMAS

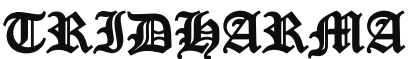

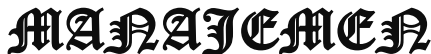

P-ISSN 0000-0000, E-ISSN 0000-0000

Jurnal ABDIMAS Vol. 1, No. 1,Agustus 2019, Hal (60-65)

@Prodi Manajemen Fakultas Ekonomi Universitas Pamulang

Email: abdimasjurnal.unpam@ gmail.com Telp: (021) 741-2566

\section{PENDAHULUAN}

Pada era Globalisasi seperti sekarang ini dimana dengan begitu pesatnya perkembangan Teknologi Informasi (TI) sudah menguasai hampir seluruh sektor bidang, menuntut generasi muda harus mampu mengikuti laju pertumbuhan ilmu tersebut sehingga tidak tertinggal informasi. Apalagi generasi muda pada saat akan memasuki usia produktif adalah usia yang paling membingungkan sepanjang masa.

Perjalanan karier yang masih belum jelas, ditambah pertengkaran dalam hubungan asmara membuat semuanya menjadi runyam. Tidak sedikit generasi muda saat ini atau biasa disebut generasi milenial yang akhirnya dilanda stres akibat memikirkan semua beban dalam hidupnya.

Oleh karena itu, mereka perlu dibekali dengan berbagai macam problem solving untuk menghadapi tantangan serta mampu bersaing dalam kancah dunia industri di masa depan.

Fenomena di lingkungan kita, saat memasuki tingkat akhir sebagian besar para siswa/siswi dibayangi oleh rasa takut dan ragu dalam memilih tujuan mereka setelah lulus sekolah. Untuk itu sudah menjadi tugas kita agar mereka memiliki kepercayaan diri dalam menentukan arah hidup mereka.

Dengan adanya materi ini tentang bagaimana bagaimana cara menentukan pilihan setelah lulus sekolah, melanjutkan pendidikan, bekerja atau membantu orang tua bekerja. Dengan demikian pemikiran siswa menjadi terbuka dan mampu mengatur arah hidup mereka secara mandiri dan bermanfaat untuk orang lain. Oleh karena itu, perlu adanya dukungan dan pihak Yayasan untuk menjalankan pelatihan ini agar tersampaikan dengan maksimal.

\section{RUMUSAN MASALAH}

Dengan mempertimbangkan latar belakang yang telah diutarakan diatas kami berinisiatif untuk membentuk pengabdian kepada masyarakat (PKM) bagi guru, orang tua dan siswa/i dilingkungan Sekolah Menengah Kejuruan (SMK) Darussalam, Ciputat, Tangerang Selatan melalui program mentoring dan motivating kepada siswa/i dalam melatih kemandirian siswa/i oleh para Dosen Universitas Pamulang dengan tujuan membekali pada siswa dan guru, orang tua siswa cara-cara dan metode yang dapat diterapkan dalam kegiatan sehari-hari.

\section{TUJUAN PELAKSANAAN}

1. Membantu memberikan arahan dan bimbingan terhadap siswa/siswi di SMK Darussalam.

2. Membuka paradigma siswa/siswi dan guru di lingkungan SMK Darussalam. 


\section{JURNAL ABDIMAS

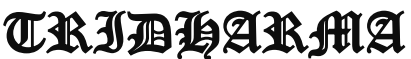

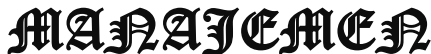

P-ISSN 0000-0000, E-ISSN 0000-0000

Jurnal ABDIMAS Vol. 1, No. 1,Agustus 2019, Hal (60-65)

@ Prodi Manajemen Fakultas Ekonomi Universitas Pamulang

Email: abdimasjurnal.unpam@ gmail.com Telp: (021) 741-2566
3. Memberikan semangat dan motivasi bagi siswa/siswi di lingkungan SMK Darussalam.

\section{TINJAUAN PUSTAKA}

\section{Pengertian Motivasi}

Motivasi dalam Bahasa Indonesia, berasal dari kata motif yang berarti daya upaya yang mendorong seseorang melakukan sesuatu.

Menurut John W. Santrock, motivasi adalah proses memberi semangat, arah, dan kegigihan perilaku. Artinya, perilaku yang termotivasi adalah perilaku yang penuh energi, terarah dan bertahan lama.

Menurut Sadirman, motif dapat dikatakan sebagai daya penggerak dari dalam diri subyek untuk melakukan aktivitas tertentu demi mencapai tujuan. Motif tersebut menjadi dasar kata motivasi yang dapat diartikan sebagai daya penggerak yang telah menjadi aktif.

Motif dapat dikatakan sebagai daya penggerak dari dalam diri subyek untuk melakukan aktivitas tertentu demi mencapai tujuan. Motif tersebut menjadi dasar kata motivasi yang dapat diartikan sebagai daya penggerak yang telah menjadi aktif.

Motif adalah sesuatu yang ada dalam diri seseorang, yang mendorong orang tersebut untuk bersikap dan bertindak guna mencapai tujuan tertentu. Motif merupakan tahap awal dari motivasi. Motif yang telah menjadi aktif inilah yang disebut motivasi. Motivasi dapat didefinisikan sebagai segala sesuatu yang menjadi pendorong tingkah laku yang menuntut atau mendorong seseorang untuk memenuhi kebutuhan.

Dari pengertian maupun definisi motivasi para ahli diatas maka dapat disimpulkan bahwa motivasi merupakan suatu keadaan atau kondisi yang mendorong, merangsang atau menggerakan seseorang untuk melakukan sesuatu atau kegiatan yang dilakukannya sehingga ia dapat mencapai tujuannya.

\section{Pengertian Mentoring}

$\begin{array}{lr} & \text { Mentoring diartikan sebagai } \\ \text { proses } \quad \text { membentuk } & \text { dan } \\ \text { mempertahankan hubungan yang } & \text { yan } \\ \text { berkembang dan berlangsung } & \text { secara } \\ \text { intensif antara pelatih dan peserta. }\end{array}$

$$
\text { Mentoring adalah suatu }
$$

hubungan antara 2 orang yang memberikan kesempatan untuk saling berdiskusi dan menghasilkan refleksi, reaksi, melakukan kegiatan atau tugas dan pembelajaran untuk keduanya yang didasarkan kepada dukungan, kritik yang membangun, keterbukaan, kepercayaan, penghargaan dan keinginan untuk belajar serta berbagi ilmu, pengetahuan dan pengalaman.

Mentoring juga merupakan sebuah metode pengembangan dimana seorang mentor akan mengajarkan tips trik, sharing pengalaman sukses, metode sukses, cara-cara sukses sesuai dengan pengalaman mentor. Seorang mentor adalah orang yang sukses di bidangnya dimana nantinya dia akan menularkan ilmunya kepada orang lain agar bisa sukses seperti dirinya. Jadi tugas seorang mentor adalah 


\section{JURNAL ABDIMAS

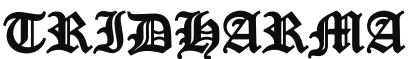

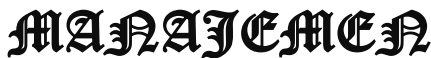

P-ISSN 0000-0000, E-ISSN 0000-0000

Jurnal ABDIMAS Vol. 1, No. 1,Agustus 2019, Hal (60-65)

@ Prodi Manajemen Fakultas Ekonomi Universitas Pamulang

Email: abdimasjurnal.unpam@ gmail.com Telp: (021) 741-2566 mendampingi seseorang (mentee) dan seorang mentor harus lebih expert dari mentee-nya.

Mentoring adalah proses umpan balik yang terus menerus dan dinamis antara dua individu untuk membangun hubungan antara individu yang memiliki pengetahuan, keterampilan, informasi dan fokus pada pengembangan profesional dan pribadi.

Tujuan dari mentoring adalah memberikan dukungan kepada individu sehingga mampu mengatasi masalah yang dihadapi dengan cara menguatkan dan mengembangkan mekanisme baru yang lebih baik untuk mempertahankan kontrol diri dan mengembalikan keseimbangan yang adaptif, sehingga mampu mencari tingkat kemandirian yang lebih tinggi serta mampu mengambil keputusan secara bebas.

\section{METODE PELAKSANAAN}

Kegiatan yang dilakukan lebih kepada interaktif kepada pada siswa/i dengan memberikan arahan, bimbingan, tanya jawab bagaimana cara-cara yang paling mudah untuk dilakukan para siswa/i dalam pengambilan keputusan. Sebelum kegiatan berlangsung tim pengabdian melakukan tahap sosialisasi terlebih dahulu yaitu melakukan silaturahmi dengan Ketua Yayasan, menyampaikan maksud dan tujuan pengabdian ini, sekaligus untuk menjalin kerjasama serta menentukan jadwal kegiatan pengabdian. Pelaksana kegiatan pengabdian pada masyarakat adalah Dosen Universitas Pamulang Fakultas
Ekonomi Program Studi Manajemen sebanyak 10 orang.

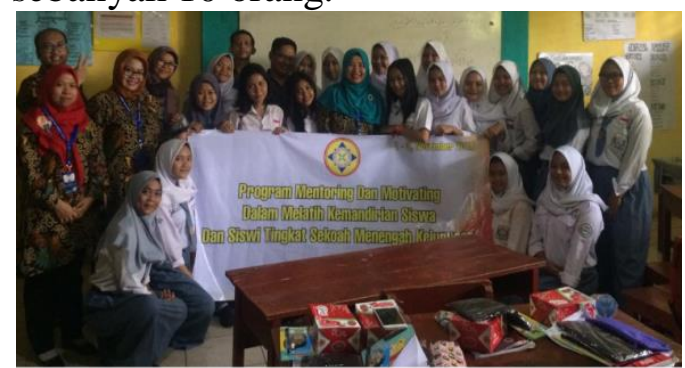

HASIL DAN PEMBAHASAN

Pengabdian Kepada Masyarakat (PKM) Universitas Pamulang yang dilakukan oleh Dosen-dosen Program Studi Manajemen telah berjalan dengan lancar dan mendapat sambutan hangat dari tempat pelaksanaan kegiatan ini yaitu di Sekolah Menengah Kejuruan (SMK) Darussalam, Ciputat, Tangerang Selatan.

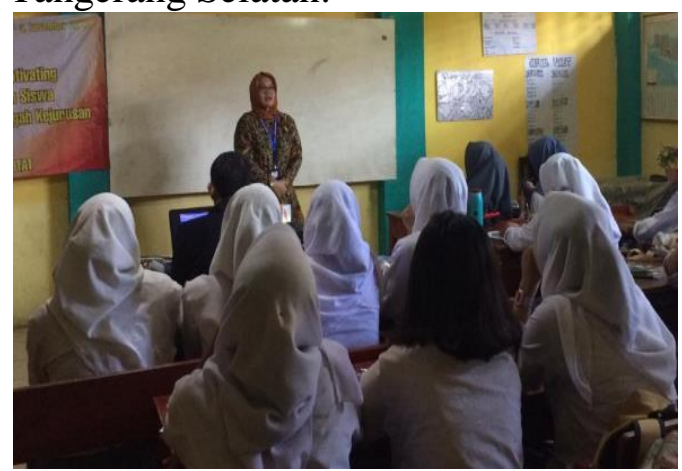

Dengan kegiatan ini diharapkan dapat membantu melatih para siswa/i menyampaikan pendapat, harapan, keinginan, berani mengambil sikap dan keputusan, memiliki rasa percaya diri serta memotivasi mereka agar menjadi generasi muda yang inovatif, kreatif, sportif, yang menjadi kebanggaan orang tua, sekolah dan masyarakat sekitarnya. 

JURNAL ABDIMAS

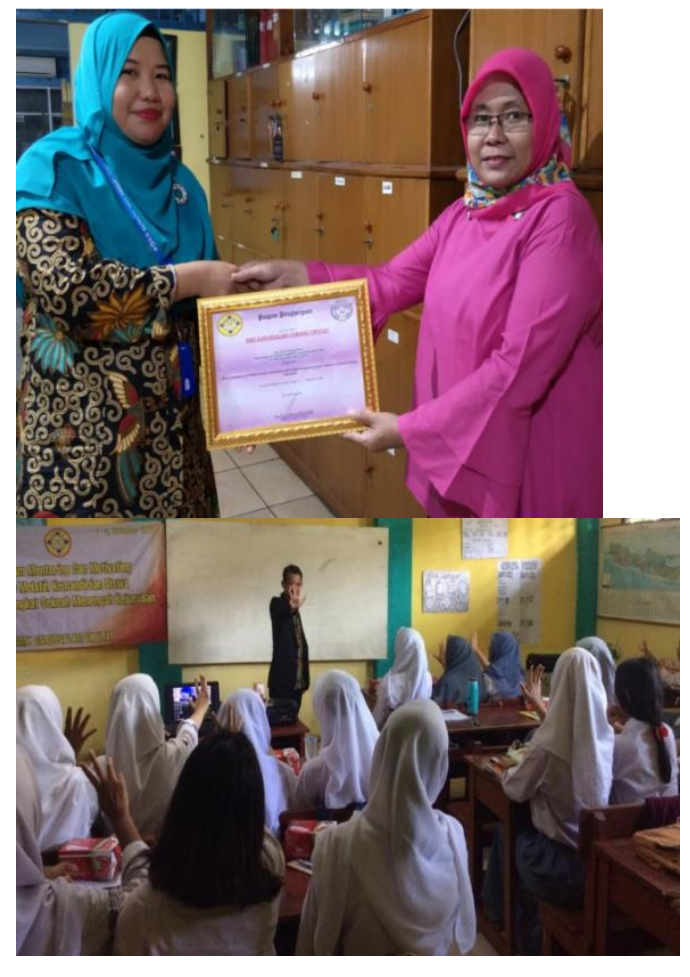

\section{KESIMPULAN DAN SARAN}

\section{Kesimpulan}

Sebagian besar para siswa/i belum berani tampil di depan umum, mereka juga sungkan, malu untuk menyampaikan pendapat, serta beberapa siswa/i mengalami kebingungan dalam menentukan langkah berikutnya setelah lulus dari sekolah.

\section{Saran}

Setelah pengabdian ini diharapkan peserta dapat membuka wawasan para siswa/i khususnya dan para guru pada umumnya, sehingga para siswa/i dapat menentukan sikap, mengambil keputusan serta melatih kemandirian dalam menentukan langkah masa depan di kemudian hari supaya menjadi anak-anak yang bermanfaat dan berhasil dalam masa yang akan datang.

\section{DAFTAR PUSTAKA}

John W. Santrock. 2010. Psikologi Pendidikan, hlm. 510.

Pasaribu, V. L. D., Susanti, F., \& Hartuti, E. T. K. (2019). MEMOTIVASI SISWA DAN SISWI SMK LETRIS INDONESIA DI DALAM MENENTUKAN PILIHAN UNTUK MELANJUTKAN PENDIDIKAN ATAU BEKERJA SETELAH LULUS SEKOLAH. Jurnal Pengabdian Dharma Laksana, 1(2), 161-172.

Rivai, H. V. \& Sagala, E. J. 2009. Manajemen Sumber Daya Manusia Untuk Perusahaan. Edisi 2 ed. Jakarta: PT. Raja Grafindo.

Sardiman A.M. 2006. Interaksi dan Motivasi Belajar Mengajar, hlm. 73.

Team Leadership: Leader as People Developer. By Michelle Kuo. Human Resource 3M Taiwan, May 21, 2015. 